\title{
BALLISTIC PERFORMANCE OF ENHANCED CROSS-LAMINATED TIMBER (ECLT)
}

\author{
KATHRYN SANBORN, BRIAN RISER, RUSSELL GENTRY \& LAUREN STEWART \\ Department of Civil and Environmental Engineering, Georgia Institute of Technology, USA
}

\begin{abstract}
Over the past 60 years, the materials traditionally used to construct temporary military structures have become less effective in operational theaters that require greater force protection from ballistic and blast events. Cross-laminated timber (CLT), an engineered wood product that has recently grown in popularity due to its strength and ease of assembly, has the potential to serve as an alternate or replacement building material. However, its viability for use in temporary military structures not only depends on its well-documented performance under normal design loads, but also its less-understood performance under ballistics and blast loading conditions. To better characterize CLT under such conditions in the absence of historical data, a series of ballistic experiments were conducted at the United States Army Engineer Research and Development Center (ERDC) to measure the penetration depth or residual velocity of munitions fired at various velocities. Based on the 152 initial ballistic experiments, new enhanced cross-laminated timber (ECLT) samples were developed using known armor materials and evaluated in terms of constructability and ballistic performance. During construction, heavy plate armor was significantly less compatible in bonding with CLT configurations and in some cases required mechanical connections, whereas the more fibrous materials developed for use in lightweight armor bonded well to the CLT with an epoxy mixture. The most promising ballistic performances came from the ECLT samples using flexible fibrous materials. In general, the testing showed that increased ballistic performance is attainable by enhancing CLT, but such improvements have consequences such as increased weight or material cost. Therefore, compromise on acceptable protection levels during the design process using cost-benefit analysis is necessary. Ultimately, ECLT samples modified with fiberglass fabric showed greatest cost-benefit potential.
\end{abstract}

Keywords: CLT, cross-laminated timber, enhanced.

\section{INTRODUCTION}

Cross-laminated timber (CLT) is a mass timber product made of engineered or natural wood. In recent years, CLT has been developed and studied as a structural building material for use in place of, or in conjunction with, concrete, masonry and steel. Due to the inherent benefits of wood as a renewable resource, interest in CLT in North America has expanded over the last decade.

CLT is formed from stacked, solid sawn lumber boards cut at various thicknesses and widths. It is composed of multiple wood lamina sub-components, typically an odd number from three to nine inches in thickness [1]. Due to wood's orthotropic properties, adjacent lamina are orientated perpendicularly to maximize each component's individual strength and produce a composite material with high strength and stiffness [2]. It follows that the weakness of each wood member, oriented with its tangential axis, is minimized [2]. Because CLT lamina are symmetrically configured, panels are highly customizable, allowing for relatively simple modifications during manufacture and in-situ with minimal waste.

In general, wood has not been considered in the design of protective structures due to its low strength compared to other materials that can effectively provide ballistic protection. However, CLT can achieve strengths greater than traditional wood components and can have advantages similar to those of steel and concrete, the most prevalent protective materials. Combined with its added benefits of lower weight and higher thermal efficiency, the viability of CLT as a potential protective material should be considered [2]. Moreover, the laminate 
nature of the CLT panels yields opportunities for introducing other non-wood materials into the composite, an especially popular concept in ballistic-resistant design.

The concept of enhanced cross-laminated timber (ECLT) is new and has no prior research, although hybrid CLT has been investigated in the past. In this context, the term hybrid refers to the concept of alternating various wood types and species, not materials other than wood [3]-[6]. The ECLT discussed in this paper is distinct in that it introduced an enhancing layer with the intent of providing improved ballistic resistance. Because ECLT involves adding layers to the original configuration, the increased weight, cost, and impact to overall structural performance such as strengths and stiffness were considered.

\section{EXPERIMENT DESCRIPTION}

The ECLT panels were manufactured at the Georgia Institute of Technology's Digital Fabrication Laboratory and transported for ballistic testing at the US Army Corps of Engineers' Engineer Research and Development Center (ERDC). The primary objective of these experiments was to determine if CLT can be modified to improve its ballistic resistance and, if so, which modifications yield the best cost-benefit ratio. At ERDC, fifteen test shots were conducted on one standard 5-ply SYP CLT panel that served as a baseline, then eightyfour test shots were conducted on the constructed ECLT specimens.

\subsection{ECLT production}

Eight variations of ECLT were made using 5-ply of Southern Yellow Pine (SYP) sawn lumber in accordance with guidelines and standards of the CLT Handbook: US Edition and Standard for Performance-Rated Cross-Laminated Timber ANSI/APA PRG 320-2012 (PRG 320) [1], [7]. The impact cross-section of each specimen was sized to 12-inch width by 12inch length $(30.5 \mathrm{~cm}$ by $30.5 \mathrm{~cm})$, with most enhancing layers placed between the second and third wood lamina to reduce the impact on the wood sub-components' other properties such as strength and stiffness. A key component of ECLT is the bond strength between the enhancing layer and the wood layers, which will be discussed more in the following sections.

Several different enhancing materials were selected based on their known properties that improved ballistic resistance, as shown in Table 1. Fig. 1 shows configurations of ECLT with mild steel and aramid epoxy enhancing layers. Some modifying layers were chosen based on their strengths and hardness, which either prevent perforation or slow projectile movement

Table 1: Enhancing layer material.

\begin{tabular}{|l|l|c|c|}
\hline \multicolumn{2}{|l|}{ Enhancing layer material } & $\begin{array}{c}\text { Thickness } \\
\text { in. }(\mathrm{cm})\end{array}$ & $\begin{array}{c}\text { Number of } \\
\text { specimens }\end{array}$ \\
\hline Type 1 & P900 perforated steel plate & $0.50(1.27)$ & 1 \\
\hline Type 2 & Expanded metal plate & $0.50(1.27)$ & 1 \\
\hline Type 3 & Aramid epoxy panel & $0.56(1.42)$ & 3 \\
\hline Type 4 & Mild steel plate & $0.25(0.63)$ & 2 \\
\hline Type 5 & High-hard steel plate & $0.25(0.63)$ & 2 \\
\hline Type 6 & $\begin{array}{l}\text { Ultra-high molecular weight } \\
\text { polyethylene (UHMWPE) }\end{array}$ & $1.00(2.54)$ & 1 \\
\hline Type 7 & Fiberglass fabric, 4-ply consolidated & $0.12(0.31)$ & 2 \\
\hline Type 8 & Fiberglass fabric, 4-ply separated & $0.12(0.31)$ & 2 \\
\hline
\end{tabular}



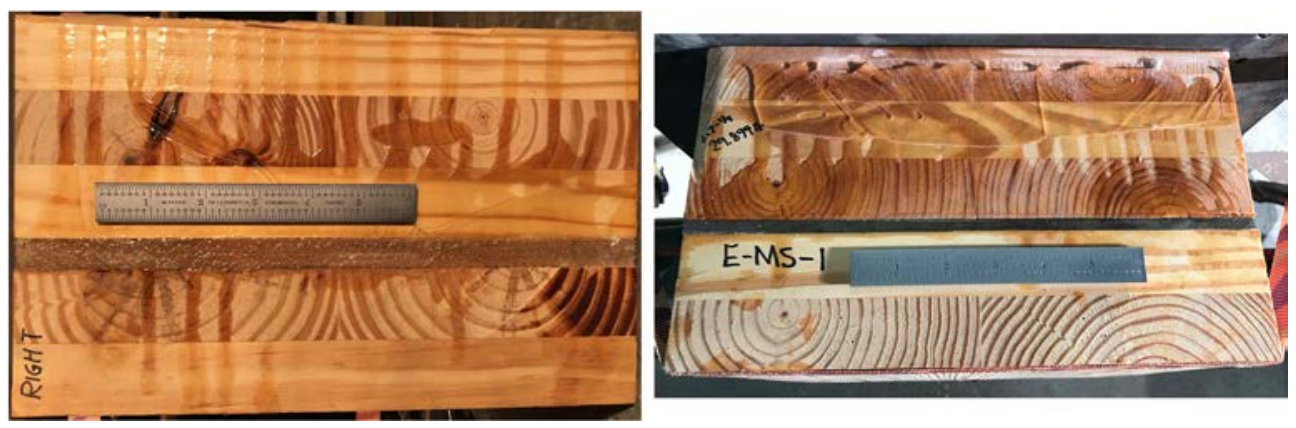

Figure 1: ECLT specimen: Type 3 - aramid epoxy panel (left); Type 4 - mild steel plate (right).

enough to prevent complete penetration. Other layers were chosen based on their ability to conform to the projectile and dissipate its energy enough across the panel's cross-sectional area to resist penetration.

\subsubsection{Type 1 - P900 perforated steel plate}

Perforated metal plates can resist multiple threats with minimum loss of performance compared to solid metal plates, while significantly reducing weight due to perforations. The staggered and slotted holes in the plate redirect projectiles upon impact, thus absorbing a significant amount of its energy. The solid metal sections, depending on the projectile type and velocity, may help to resist a projectile larger than the opening. The holes are also oriented at an angle, which limits deflection and pass-through shots [8].

One test specimen was made with the enhanced layer of P900 perforated steel plate. The plate used in this research measured 12-inches wide by 12 -inches high $(30.5 \mathrm{~cm}$ by $30.5 \mathrm{~cm})$ and 0.50 -inches $(1.27 \mathrm{~cm})$ thick. Its perforated holes were 1.1875 -inches $(0.47 \mathrm{~cm})$ wide by 0.375 -inches $(0.95 \mathrm{~cm})$ high, with a solid metal width of 0.1875 -inches $(0.47 \mathrm{~cm})$ between the holes. Due to concerns with the metal's bonding properties, the plates were mechanically affixed to the 2-ply and 3-ply sections using washer hex drive screws with 3/16-inch diameter $(0.47 \mathrm{~cm})$ and 6-inch $(15.24 \mathrm{~cm})$ length [2].

\subsubsection{Type 2 - expanded metal plate}

Expanded metal is manufactured differently than perforated metal and is typically a carbon steel sheet that has been slit and stretched into a rigid mesh with diamond shaped openings. The expanded metal is comprised of strands of metal with intersections called bonds, which form a sharp angle from the original flat sheet of metal and can divert a projectile's trajectory. Similar to perforated steel plate, expanded metal plate has a favorable strength-to-weight ratio and can either divert a projectile's trajectory or stop it at the plate after impact.

One test specimen was made with the enhanced layer of expanded metal plate. The plate used in this research measured 12-inches wide by 12 -inches $(30.5 \mathrm{~cm}$ by $30.5 \mathrm{~cm})$ high and 0.50 -inches $(1.27 \mathrm{~cm})$ thick. Its mesh was 0.875 -inches $(2.22 \mathrm{~cm})$ wide and 1.0625 -inches $(2.7 \mathrm{~cm})$ long. The individual strands were approximately 0.25 -inches $(0.635 \mathrm{~cm})$ wide and 0.50 -inches $(1.27 \mathrm{~cm})$ thick, with the openings less than 0.50 -inches $(1.27 \mathrm{~cm})$ wide [2]. The expanded metal plate was not flattened, but was instead kept uneven with the intent of redirecting, slowing down or stopping the projectile after impact. Due to concerns with the metal's bonding properties, the plates were mechanically affixed to the 2-ply and 3-ply 
sections using washer hex drive screws with 3/16-inch diameter $(0.47 \mathrm{~cm})$ and 6-inch $(15.24$ $\mathrm{cm})$ length.

\subsubsection{Type 3 - aramid epoxy panel}

An aramid epoxy panel is a rigid board composed of layers of woven aramid fibers with a polyvinyl butyral (PVB) phenolic resin. The fibers have a high strength-to-weight ratio, high structural rigidity and offer good resistance to abrasion and cutting.

Three test specimens were made with the enhanced layer of aramid epoxy panel. The panels used in this research measured 12-inches wide by 12 -inches $(30.5 \mathrm{~cm}$ by $30.5 \mathrm{~cm})$ and approximately 0.5625 -inches $(1.43 \mathrm{~cm})$ thick [2]. The enhancing layer was adhered to the two CLT sections using a two-part, resin and hardener, epoxy system. The CLT sections were surface treated and the aramid panels were lightly sanded to provide an effective adhering surface for the epoxy.

\subsubsection{Type 4 - mild steel plate}

Mild steel is a popular building material due its strength, but is typically not used in modern armor due to its relative ductility. A previous study conducted by Gupta and Madha that included mild steel plates observed complete perforation when impacted by ogive-shaped armor-piercing projectiles. Thicker mild steel targets, up to almost 1-inch $(2.54 \mathrm{~cm})$, yielded similar results with slower residual velocities, and increased petal height on the front face [9]. However, this enhancing layer was chosen to investigate if its ductility, combined with the strength of the CLT sections, could dissipate the projectile's energy without failing.

Two test specimens were made with the enhanced layer of mild steel plate. The panels used in this research measured 12-inches wide by 12-inches high $(30.5 \mathrm{~cm}$ by $30.5 \mathrm{~cm})$ and 0.25 -inches $(0.63 \mathrm{~cm})$ thick [2]. The enhancing layer was adhered to the two CLT sections using a two-part, resin and hardener, epoxy system. The CLT sections were surface treated and the steel plates were media blasted to provide an effective adhering surface for the epoxy.

\subsubsection{Type 5 - high-hard steel plate}

High-hard steel is known for its high strength and is commonly used as applique armor for hardening vehicles. Compared to mild steel, it is less ductile and has significantly greater hardness. In armor applications, it is typically heat treated to achieve even greater resistance to ballistic penetration. Although its weight and cost would make mass use in building construction unfeasible, this enhancing layer was chosen to explore the ease of ECLT production using this material and the possible delaminating effects of ballistic impact on the wood-steel interface.

Two test specimens were made with the enhanced layer of high-hard steel plate. The panels used in this research measured 12-inches wide by 12-inches high $(30.5 \mathrm{~cm}$ by 30.5 $\mathrm{cm})$ and 0.25 -inches $(0.63 \mathrm{~cm})$ thick [2]. The enhancing layer was adhered to the two CLT sections using a two-part, resin and hardener, epoxy system. The CLT sections were surface treated and the steel plates were media blasted to provide an effective adhering surface for the epoxy.

\subsubsection{Type 6 - ultra-high molecular weight polyethylene (UHMWPE)}

Ultra-high molecular weight polyethylene (UHMWPE) is a fiber-based, low-weight composite laminate with four unidirectional sheets cross plied and held together with a polyurethane-based matrix. While the exact production details are proprietary, the general process involves the fiber manufacture in a high temperature gel-spinning process and then coated in resin, stacked crosswise to the desired thickness, and hot pressed [10]. UHMWPE 
has high tensile strength at high strain rates, which makes it a good lightweight product for body armors.

One test specimen of ECLT contained an enhancing layer of ultra-high molecular weight polyethylene (UHMWPE) plastic panel. This panel measured 12-inches wide by 12 -inches high $(30.5 \mathrm{~cm}$ by $30.5 \mathrm{~cm})$ and one-inch thick $(2.54 \mathrm{~cm})$ [2]. Due to concerns with the material's bonding properties, the laminate was mechanically affixed to the 2-ply and 3-ply sections using washer hex drive screws with 3/16-inch diameter $(0.47 \mathrm{~cm})$ and 6-inch $(15.24$ $\mathrm{cm})$ length.

\subsubsection{Types 7,8 - fiberglass fabric}

Woven roving fiberglass fabric is a low-cost, high-strength material that is impact resistant. Much like aramid fabric, woven roving is composed of bundled threads oriented in two orthogonal directions with a basket-style weave. Once constructed, it has high tensile strength, retains its light-weight and is compatible with epoxy bonding. Ballistic panels are commonly made with woven roving to absorb impact as well as trap shrapnel and spall in the plies. The material is often combined with other materials including foam core and concrete to form composite panels. Hybrid products using both carbon and glass fibers are have also been the subject of ballistic impact studies [11]-[13].

Four test specimens of ECLT contained enhancing layers of fiberglass fabric using two distinct configurations. Each layer of fiberglass fabric measured 12-inches wide by 12-inches high $(30.5 \mathrm{~cm}$ by $30.5 \mathrm{~cm})$ and nominally 0.030 -inches $(7.62 \mathrm{~mm})$ thick [2]. Two specimens were configured using four consolidate layers of fiberglass fabric placed between the second and third ply of CLT. The other two specimens were configured using four separate layers of fiberglass fabric individually placed between each internal wood lamina. Both configurations used an epoxy resin adhesive to bond the fiberglass fabric to the wood, although the separate layer configuration also required polyurethane adhesive.

\subsection{Test set-up and methodology}

The experimental test set-up at ERDC consisted of an indoor, conditioned, ballistic range with a table-mounted smooth bore powder gun with a 50-caliber barrel firing 0.5 -inch $(1.27$ $\mathrm{cm})$ spherical projectiles [2]. Fig. 2 shows the firing apparatus. Four infrared photoelectric velocity screens were connected to two chronographs to capture two different velocity measurements as the projectile moved toward the target. The data from the screens was used to determine the striking velocity, $\mathrm{v}_{\mathrm{s}}$, based on the measured velocities and known distances between each of the screens and between the final screen and target. The CLT specimens were secured to a floor-mounted steel frame using ratchet straps, which enabled the specimens to be repositioned easily.

Two types of ballistic data were gathered depending on the effect of the shot. If the projectile perforated the CLT specimen, then a residual velocity $\left(\mathrm{V}_{\mathrm{r}}\right)$ was recorded based on the high-speed video capturing the round exiting the back face of the specimen. If the shot yielded only partial penetration and the projectile remained embedded in the specimen, then the depth of penetration (d) was recorded. Ballistics testing is inherently variable as even factory-produced munitions shoot at a range of velocities, thus the goal with these experiments was to shoot multiple shots at the same approximate striking velocity across all specimen for comparison [2]. The target velocity for all tests was 2,500 fps (762 m/s). 


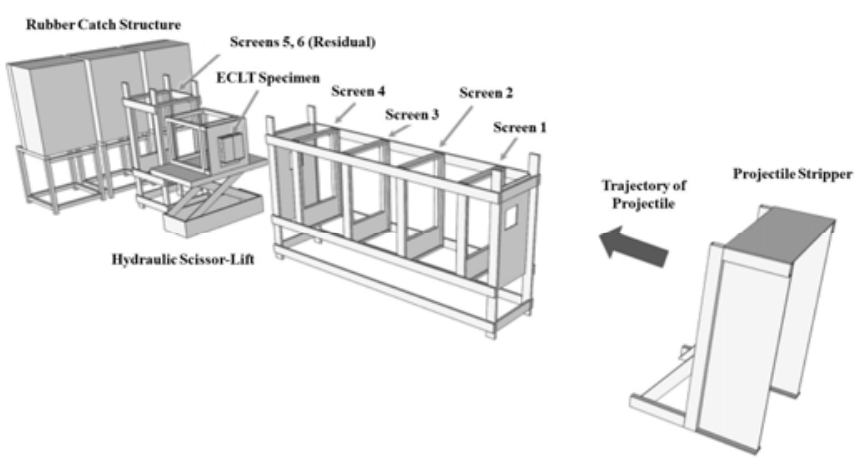

Figure 2: Setup for ballistic experiments at the US Army Engineer Research and Development Center. (Source: Sanborn [2].)

\section{EXPERIMENT RESULTS}

All specimens, excluding those with the fiberglass fabric, experienced only partial penetration. Table 2 displays the average striking velocities and penetration depths of each ECLT variation for a target striking velocity of 2,500 fps $(762 \mathrm{~m} / \mathrm{s})$.

\subsection{Performance of Type 1 - P900 perforated steel plate}

One specimen of ECLT enhanced with P900 perforated plate was tested. The specimen was subjected to seven shots with 0.50 -inch sphere projectiles at an average striking velocity of $2,528 \mathrm{fps}(770.5 \mathrm{~m} / \mathrm{s})$. The average penetration depth for all seven projectiles was 3.42 inches $(8.69 \mathrm{~cm})$. Although there were no complete perforations, the projectiles penetrated beyond the enhancing layer [2]. All penetrations were less than 0.5 -inches, indicating that the enhancing layer dissipated enough of the projectile's energy to allow only a shallow penetration. Shots close to the steel plate perforations resulted in deeper penetrations, demonstrating that the perforations influenced the penetration depth.

Table 2: Performance of ECLT specimen at target striking velocity, Types 1-6 [2].

\begin{tabular}{|c|c|c|c|c|c|c|c|}
\hline \multirow{2}{*}{\multicolumn{2}{|c|}{ Enhancing layer material }} & \multirow{3}{*}{$\begin{array}{c}\text { Specimen } \\
\text { quantity }\end{array}$} & \multirow{3}{*}{$\begin{array}{c}\text { Shots } \\
7\end{array}$} & \multicolumn{2}{|c|}{$\begin{array}{c}\text { Average } \\
\text { striking } \\
\text { velocity, } \mathrm{v}_{\mathrm{s}} \\
\end{array}$} & \multicolumn{2}{|c|}{$\begin{array}{l}\text { Average } \\
\text { penetration } \\
\text { depth, d }\end{array}$} \\
\hline & & & & fps & $\mathrm{m} / \mathrm{s}$ & in & $\mathrm{cm}$ \\
\hline Type 1 & $\begin{array}{l}\text { P900 perforated steel } \\
\text { plate }\end{array}$ & & & 2,528 & 770.5 & 3.42 & 8.7 \\
\hline Type 2 & Expanded metal plate & 1 & 8 & 2,543 & 775.1 & 3.61 & 9.2 \\
\hline Type 3 & Aramid epoxy panel & 2 & 15 & 2,513 & 766.0 & 4.56 & 11.6 \\
\hline Type 4 & Mild steel plate & 2 & 10 & 2,585 & 787.9 & 2.79 & 7.1 \\
\hline Type 5 & High-hard steel plate & 2 & 10 & 2,526 & 770.0 & 2.53 & 6.4 \\
\hline Type 6 & $\begin{array}{l}\text { Ultra-high molecular } \\
\text { weight polyethylene } \\
\text { (UHMWPE) }\end{array}$ & 1 & 5 & 2,503 & 762.9 & 2.35 & 6.0 \\
\hline
\end{tabular}




\subsection{Performance of Type 2 - expanded metal plate}

One specimen of ECLT enhanced with expanded metal plate was tested. The specimen was subjected to eight shots with 0.50 -inch $(1.27 \mathrm{~cm})$ sphere projectiles at an average striking velocity of $2,543 \mathrm{fps}(775.1 \mathrm{~m} / \mathrm{s})$. The average penetration depth was 3.61 inches $(9.17 \mathrm{~cm})$. There were no complete perforations. Multiple projectiles were stopped at the surface of the enhancing layer due to slightly smaller perforations compared to the P900 steel plate. Again, the location of the shot with respect to the perforation pattern affected penetration depth; projectiles that impacted a bond were more effective than those that hit a single strand [2]. All fractured metal was contained within the CLT panel, minimizing shrapnel concerns.

\subsection{Performance of Type 3 - aramid epoxy panels}

Three specimens of ECLT enhanced with aramid epoxy panel were tested. Two specimens were subjected to a total of 15 shots with 0.50 -inch sphere projectiles at an average striking velocity of 2,513 fps $(766.0 \mathrm{~m} / \mathrm{s})$. The average penetration depth was 4.56 inches $(11.58 \mathrm{~cm})$, indicating that the projectiles were stopped in the first play of the rear CLT section just beyond the enhancing layer. There were no complete perforations and no indication of delamination toward the edges of the striking face. The back face of the specimens was not visibly damaged.

To determine the limiting striking velocity of the Type 3 configuration, the third specimen was subjected to projectiles with higher striking velocities. Six shots were completed with a minimum striking velocity of 2,851 fps $(869 \mathrm{~m} / \mathrm{s})$ and a maximum of 3,041 fps $(927 \mathrm{~m} / \mathrm{s})$. The three greatest striking velocities achieved complete perforation, while the three slower striking velocities achieved only partial penetration. The third specimen resisted complete perforation until a striking velocity of 2,992 fps $(912.0 \mathrm{~m} / \mathrm{s})$.

\subsection{Performance of solid steel plates}

While both solid steel plate configurations successfully stopped all projectiles at their enhancing layers, two different failure modes resulting from varying ductility and hardness between the two steel types were observed: bulging and plugging. Due to the contrast of the
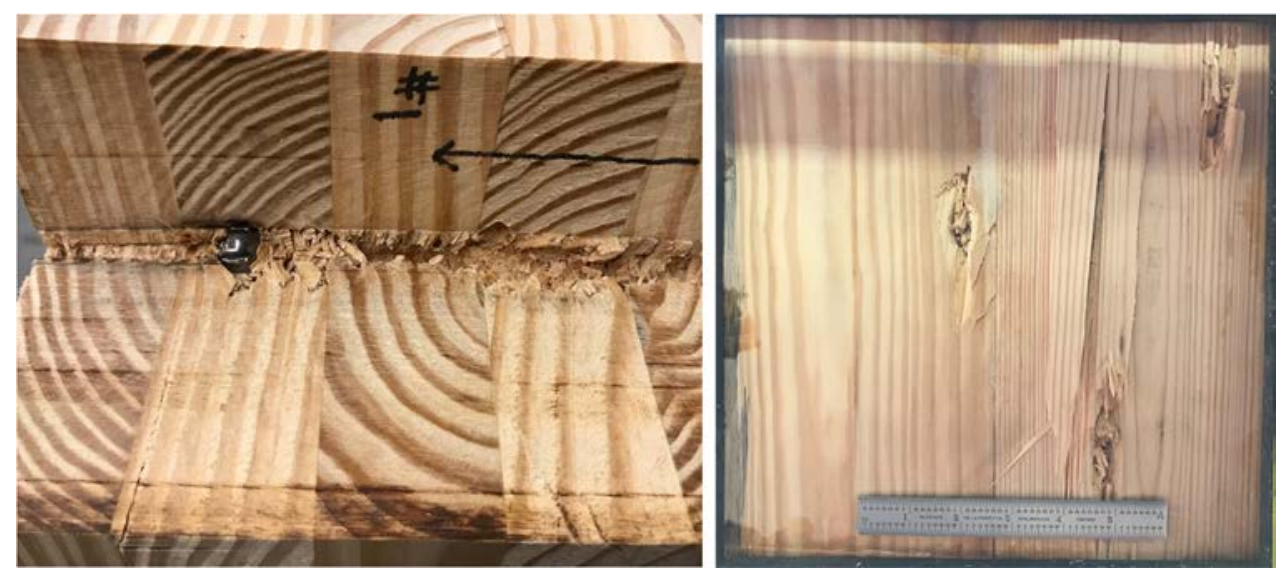

Figure 3: Characteristic path of projectile through wood lamina (left), complete perforation of three projectiles through third Type 3 ECLT specimen (right). 
wood's natural curvature and the steel's flat surface, gaps were observed between the wood and steel after application of the adhesive epoxy mixture. This suggests possible inconsistent adhesion between the wood and the steel plate [2]. Despite these gaps, the bond appeared secure once dried and there was no movement upon application of static load to the specimens.

\subsubsection{Type 4 - mild steel}

Two specimens of ECLT enhanced with mild steel plates were tested. The specimens were subjected to a total of 10 shots with 0.50 -inch $(1.27 \mathrm{~cm})$ sphere projectiles at an average striking velocity of $2,585 \mathrm{fps}(787.9 \mathrm{~m} / \mathrm{s})$. The average penetration depth was 2.79 -inches $(7.1 \mathrm{~cm})$, indicating that the projectiles penetrated through the front CLT section but were stopped entirely by the steel plate. The projectiles embedded in the steel plate which, due to the plate's ductility, resulted in significant bulging on its rear side and indentions on the rear 3-ply CLT section.

Following the initial shot, small fractures developed in the wood and grew after successive shots toward the outer edges of the front and back sides of the steel interface. Although not evidence of complete delamination between the steel and wood, this cracking indicates the presence of high stresses in the interface between the two materials, likely the result of gaps formed by inconsistent adhesion.

\subsubsection{Type 5 - high-hard steel}

Two specimens of ECLT enhanced with high-hard steel plates were tested. The specimens were subjected to a total of 10 shots with 0.50 -inch sphere projectiles at an average striking velocity of $2,526 \mathrm{fps}(770.0 \mathrm{~m} / \mathrm{s})$. The average penetration depth was 2.53 inches $(6.4 \mathrm{~cm})$, indicating that the projectiles penetrated through the front CLT section, but were stopped entirely by the steel plate. Instead of bulging like the mild steel plate, the high-hard steel failed by plugging, indicated by holes in the steel plate and cylindrical slugs embedded in the rear CLT section beyond the enhancing layer [2]. Damage to the projectiles indicated yielding against the harder steel plate.

Unlike the ECLT enhanced with mild steel plate, fractures developed in the wood after the third or fourth shots and propagated toward the outer edges of the front and back sides of the steel interface with successive shots. This difference is likely due to the greater stiffness of high-hard steel, which results in less movement in response to ballistic impact [2]. Similar to the mild steel plate configuration, the fractures indicate high stresses in the interface between the two materials, likely the result of gaps formed by inconsistent adhesion.

\subsection{Performance of Type 6 - ultra-high molecular weight polyethylene (UHMWPE)}

One specimen of ECLT enhanced with ultra-high molecular weight polyethylene (UHMWPE) panels were tested. The specimen was subjected to five shots with 0.50 -inch $(1.27 \mathrm{~cm})$ sphere projectiles at an average striking velocity of 2,503 fps $(762.9 \mathrm{~m} / \mathrm{s})$. The average penetration depth was 2.35 -inches $(6.0 \mathrm{~cm})$, indicating that the projectiles penetrated through the front CLT section, but were stopped entirely by the front of UHMWPE panel. After the second shot, a small crack aligned with that projectile's entry hole developed on the side of the front 2-ply CLT section, suggesting that the panel's energy dissipation caused internal stresses in the CLT sections through the panel's mechanical connections [2]. Alternatively, the crack could have simply propagated from the projectile's entry hole along a flaw or grain line toward the edge of the specimen. 
After the initial five shots were completed at the target striking velocity, the specimen was subjected to three additional shots at higher striking velocities to determine this ECLT configuration's limiting striking velocity. One projectile with a striking velocity of 4,169 fps $(1,271 \mathrm{~m} / \mathrm{s})$ resulted in complete perforation of the ECLT specimen. The projectile's residual velocity upon exit was $560 \mathrm{fps}(171 \mathrm{~m} / \mathrm{s})$. For all three additional shots, the magnitude of internal strains within the enhancing layer caused radial and tangential cracking of the wood plies on both sides of the panel [2]. Similar to the mild steel plate configuration, bulging of the UHMWPE panel occurred on its front and back faces, causing indentations in the rear 3-ply CLT section beyond the enhancing layer. In general, the specimen withstood high velocities with minimal impact to the CLT.

\subsection{Performance of Type 7 - fiberglass fabric, 4-ply consolidated}

Two specimens of ECLT enhanced with the four consolidated layers of fiberglass fabric were tested. Table 3 summarizes the mixed results for each specimen in terms of projectile penetration and residual velocity. The first specimen was subjected to 5 shots with 0.50 -inch $(1.27 \mathrm{~cm})$ sphere projectiles at an average striking velocity of 2,463 fps $(750.7 \mathrm{~m} / \mathrm{s})$. The average penetration depth was 5.95 -inches $(15.1 \mathrm{~cm})$, indicating that the projectiles penetrated through the front CLT section, through the enhancing layer, and well into the rear CLT section. No complete penetrations occurred, although wood splintering was observed on the rear face of the specimen.

The second specimen was also subjected to five shots at comparable striking velocities. This resulted in two complete penetrations, characterized by wood petaling on the rear face of the specimen and stretch and brittle failure of the enhancing layer. One of the complete penetrations occurred after the fastest striking velocity in the shot series, while the other occurred after the slowest striking velocity in that series.

\subsection{Performance of Type 8 - fiberglass fabric, 4-ply separated}

Two specimens of ECLT enhanced with the four separated layers of fiberglass fabric were tested. Table 4 summarizes the mixed results for each specimen in terms of projectile penetration and residual velocity. The first specimen was subjected to 5 shots with 0.50 -inch $(1.27 \mathrm{~cm})$ sphere projectiles at an average striking velocity of 2,503 fps $(762.9 \mathrm{~m} / \mathrm{s})$. The average penetration of depth was 5.76 inches $(14.6 \mathrm{~cm})$, indicating that the projectiles penetrated through the front CLT section, through the enhancing layer, and continued well into the CLT section. The second shot of the series resulted in complete penetration, yielding a residual velocity of $176 \mathrm{fps}(53.6 \mathrm{~m} / \mathrm{s})$ out the rear face of the specimen.

Table 3: Performance of ECLT specimen at target striking velocity, Type 7.

\begin{tabular}{|c|c|c|c|c|c|c|c|}
\hline \multirow{3}{*}{ Specimen } & \multirow{2}{*}{ Shot } & \multicolumn{2}{|c|}{$\begin{array}{c}\text { Striking } \\
\text { Velocity, }\end{array}$} & \multicolumn{2}{c|}{$\begin{array}{c}\text { Penetration } \\
\text { Depth, }\end{array}$} & \multicolumn{2}{c|}{$\begin{array}{c}\text { Residual } \\
\text { Velocity, }\end{array}$} \\
\cline { 3 - 8 } & & $\mathrm{fps}$ & $\mathrm{m} / \mathrm{s}$ & $\mathrm{in}$ & $\mathrm{cm}$ & $\mathrm{fps}$ & $\mathrm{m} / \mathrm{s}$ \\
\hline 1 & Average & 2,463 & 750.7 & 5.95 & 15.1 & - & - \\
\hline \multirow{5}{*}{2} & 1 & 2,463 & 750.7 & 6.44 & 16.4 & - & - \\
\cline { 2 - 8 } & 2 & 2,462 & 750.4 & - & - & 301 & 91.7 \\
\cline { 2 - 8 } & 3 & 2,484 & 757.1 & 6.25 & 15.9 & - & - \\
\cline { 2 - 8 } & 4 & 2,492 & 759.6 & - & - & 327 & 99.7 \\
\cline { 2 - 8 } & 5 & 2,468 & 752.2 & 6.63 & 16.8 & - & - \\
\hline
\end{tabular}


Table 4: Performance of ECLT specimen at target striking velocity, Type 8.

\begin{tabular}{|c|c|c|c|c|c|c|c|}
\hline \multirow{3}{*}{ Specimen } & \multirow{2}{*}{ Shot } & \multicolumn{2}{|c|}{$\begin{array}{c}\text { Striking } \\
\text { Velocity, }\end{array}$} & \multicolumn{2}{c|}{$\begin{array}{c}\text { Penetration } \\
\text { Depth, d }\end{array}$} & \multicolumn{2}{c|}{$\begin{array}{c}\text { Residual } \\
\text { Velocity, }\end{array}$} \\
\cline { 3 - 8 } & & $\mathrm{fps}$ & $\mathrm{m} / \mathrm{s}$ & $\mathrm{in}$ & $\mathrm{cm}$ & $\mathrm{fps}$ & $\mathrm{m} / \mathrm{s}$ \\
\hline \multirow{5}{*}{1} & 1 & 2,484 & 757.1 & 5.75 & 14.6 & - & - \\
\cline { 2 - 8 } & 2 & 2,632 & 802.2 & - & - & 176 & 53.6 \\
\cline { 2 - 8 } & 3 & 2,402 & 732.1 & 5.34 & 13.6 & - & - \\
\cline { 2 - 8 } & 4 & 2,472 & 753.5 & 5.81 & 14.8 & - & - \\
\cline { 2 - 8 } & 5 & 2,527 & 770.2 & 6.13 & 15.6 & - & - \\
\hline 2 & Average & 2,430 & 740.7 & - & - & 568 & 173 \\
\hline
\end{tabular}

The second specimen was also subjected to five shots at comparable striking velocities, but resulted in five complete penetrations, especially in the third and fourth enhancing layers. Again, the complete penetrations were characterized by wood petaling on the rear face of the specimen and stretch and brittle failure of the enhancing layer. The average residual velocities were $568 \mathrm{fps}(173.0 \mathrm{~m} / \mathrm{s})$.

The decrease in overall performance observed between the Type 7 and Type 8 ECLT variations suggests that the configuration of fiberglass fabric layers could be a significant factor in ballistic resistance, but this must be confirmed with more testing. Compared to the standard 5-ply CLT panel, which suffered complete penetration with every shot, the Type 8 ECLT variation contained four projectiles and significantly decreased the residual velocities of those projectiles that did penetrate the specimen.

\section{COST-BENEFIT ANALYSIS}

In conducting a cost to benefit analysis, it is imperative to define the benefit. Many contributing factors could be used to assess the benefit, such as: ease of production, ease of constructability, availability of material, ballistic resistance, and weight for logistical considerations if applicable. For simplicity, the cost benefit analysis presented in Table 5 limits the assessment to a ballistic resistance ranking and cost by weight values. Many armor materials are priced by their cost per weight, but the areal density of the material should also be considered and is covered in detail by Sanborn [2]. In this example, the rankings with low values represent better performance and serve as the benefit metric.

Using the experimental results of this research with the 0.50 -inch sphere projectile, a ballistic resistance ranking was determined subjectively for each enhancing layer based on the quantity of complete and partial penetrations, the percentage of penetrations beyond the enhancing layer, and maximum depth of penetration. Table 5 shows the relevant data for the assessment and ranking of the various materials. The standard 5-ply CLT panel is included for baseline comparison. Only shots in the target striking velocity of 2,500 fps (762 m/s) were considered.

Each material was ranked for its cost per weight using known material weights and undiscounted vendor price estimates as of 2018 provided by the Army Research Lab [14]. The benefit cost ratio (BCR) is the calculated ratio of the ballistic resistance ranking to the cost per weight ranking. Each BCR was then ranked, providing the best ranking to highest $\mathrm{BCR}$, for comparison with the other rankings.

Using this technique with the ballistic resistance as the assessed benefit, the standard 5-ply CLT panel achieved the highest BCR. Although the panel had the lowest ballistic resistance, it had no additional cost. The Type 7 fiberglass fabric ECLT variation ranked 
Table 5: Enhancing layer material.

\begin{tabular}{|c|c|c|c|c|}
\hline \multirow[b]{2}{*}{ Enhancing layer material } & \multirow[b]{2}{*}{$\begin{array}{l}\text { Ballistic } \\
\text { resistance } \\
\text { ranking }\end{array}$} & \multicolumn{3}{|c|}{ Cost per weight $(\$ / \mathrm{lb})$} \\
\hline & & $\begin{array}{c}\text { Cost per } \\
\text { weight } \\
\text { ranking }\end{array}$ & $\begin{array}{c}\text { Benefit- } \\
\text { cost } \\
\text { ratio } \\
(\mathrm{BCR})\end{array}$ & $\begin{array}{c}\text { BCR } \\
\text { ranking }\end{array}$ \\
\hline Standard 5-ply CLT panel (Baseline) & 9 & 1 & 9.00 & 1 \\
\hline P900 perforated steel plate & 5 & 7 & 0.71 & 7 \\
\hline Expanded metal plate & 4 & 3 & 1.33 & 5 \\
\hline Aramid epoxy panel & 6 & 8 & 0.75 & 6 \\
\hline Mild steel plate & 3 & 2 & 1.50 & 3 \\
\hline High-hard steel plate & 2 & 4 & 0.50 & 8 \\
\hline $\begin{array}{l}\text { Ultra-high molecular weight } \\
\text { polyethylene (UHMWPE) }\end{array}$ & 1 & 9 & 0.11 & 9 \\
\hline Fiberglass fabric, 4-ply consolidated & 7 & 5 & 1.40 & 4 \\
\hline Fiberglass fabric, 4-ply separated & 8 & 5 & 1.60 & 2 \\
\hline
\end{tabular}

second due its increased performance, low weight, and low cost. The mild-steel plate ECLT variation ranked third. In this example, if the 0.50 -in. sphere with a striking velocity of 2,500 fps $(762 \mathrm{~m} / \mathrm{s})$ were the specified threat and the design requirement was to prevent all perforations, then the mild steel plate ECLT is the best option for cost by weight, as the standard CLT panel and the Type 7 fiberglass fabric ECLT variation failed to prevent all complete perforations. Of note, new and advanced fiber-based materials, such as aramid and UHMWPE, are significantly more costly than the metal plates and fiberglass fabric.

To expand on this benefit cost ratio assessment, additional factors beyond just cost and the simplified ballistic resistance ranking may be incorporated. Also, the assessment could be modified by assigning a weight factor to the costs or benefits based on relative importance.

\section{CONCLUSIONS}

The layered nature of CLT allows its composition to be modified for design requirements, such as ballistic resistance. Various ECLT specimens were fabricated and tested for ballistic resistance. With one exception, this research limited the enhancing layer to one centrally placed in the CLT panel. With additional testing, other configurations can be examined to optimize the placement of the enhancing layer.

ECLT specimens with solid steel plates exhibited greater ballistic resistance than standard CLT. Those with perforated metal plates performed comparably to those with solid steel plates, but were less heavy. Specimens with fiber-based ballistic panels also increased the ballistic resistance of the panel and were significantly lighter than the product with metal plates. The fiber-based materials also bonded well to the CLT with an epoxy mixture. Finally, four very thin fiberglass fabric layers notably improved the specimen's ballistic resistance, although some perforating shots were observed.

Cost-benefit assessment is critical to structural design for ballistic resistance. This paper used an example to illustrate the compromise between the expense of enhancing materials and their structural benefit. Despite the excellent performance, fiber-based ballistic panels are very expensive. The standard 5-ply CLT panel consistently achieved the best BCR based on cost by weight, although it performed poorly compared to ECLT. If only ballistic 
performance and cost by weight are considered, ECLT with steel plates achieved the best cost-benefit balance.

Based on the results of these experiments, it is evident that different specimens should be produced and tested to optimize the key factors of an ECLT panel configuration, such as: type of enhancing layer, location of enhancing layer along CLT panel depth, cost and weight of enhancing material. Additional research in this area would greatly improve specialized uses for CLT, particularly for temporary military structures.

\section{ACKNOWLEDGEMENTS}

This work was partially supported by the United States Forest Service (USFS) through the Wood Innovations Grant under USFS Domestic Grant 17-DG-11083150-008. Any opinions, findings, and conclusions or recommendations expressed in this material are those of the authors and do not necessarily reflect the views of the United States Forest Service. The authors would like to acknowledge the support of Dr Richard McGee, Mr Don Little, Dr Bill Heard, and Dr Jesse Sherburn at the US Engineer Research and Development Center, the support of Mr Charles Randow and the US Army Research Lab, and the support of Dr Christopher Conley and the United States Military Academy for their assistance with the experimental program.

\section{REFERENCES}

[1] Karacabeyli, E. \& Douglas, B., CLT Handbook (Cross-Laminated Timber), U.S. Edition, 2013.

[2] Sanborn, K., Exploring Cross-Laminated Timber Use for Temporary Military Structures: Ballistic Considerations. PhD thesis, Georgia Institute of Technology: Atlanta, GA, 2018.

[3] Aicher, S., Hirsch, M. \& Christian, Z., Hybrid cross-laminated timber plates with beech wood cross-layers. Construction and Building Materials, 124, pp. 1007-1018, 2016.

[4] Davids, W.G. et al., Structural performance of hybrid SPFs-LSL cross-laminated timber panels. Construction and Building Materials, 149, pp. 156-163, 2017.

[5] Wang, Z. et al., Planar shear and bending properties of hybrid CLT fabricated with lumber and LVL. Construction and Building Materials, 151, pp. 172-177, 2017.

[6] Wang, Z., Gong, M. \& Chuim Y.H., Mechanical properties of laminated strand lumber and hybrid cross-laminated timber. Construction and Building Materials, 101, pp. 622-627, 2015.

[7] The Engineered Wood Association, American National Standard: Standard for Performance-Rate Cross-Laminated Timber ANSI/APA PRG 320-2012, APA: Tacoma, WA, 2012.

[8] Performance Specification: Perforated Homogeneous Steel Armor, eds DOT Army, Army Research Laboratory, Aberdeen Proving Ground, MD, Weapons and Materials Research Directorate, Materials Applications Branch, and Specifications and Standards Office, 2007.

[9] Gupta, N.K. \& Madha, V., An experimental study of normal and oblique impact of hard-core projectile on single and layered plates. International Journal of Impact Engineering, 19, pp. 395-414, 1997.

[10] van Dingenen, J.L.J., High performance dyneema fibres in composites. Materials \& Design, 10, pp. 101-104, 1989.

[11] Pandya, K.S., Pothnis, J.R., Ravikumar, G. \& Naik, N.K., Ballistic impact behavior of hybrid composites. Materials \& Design, 44, pp. 128-135, 2013. 